\title{
A registry based analysis of the patient reported outcome after surgery for trapeziometacarpal joint osteoarthritis
}

\author{
Maria Wilcke ${ }^{1,2^{*}} \mathbb{D}$, Martin Roginski ${ }^{1,2}$, Mikael Åström³ and Marianne Arner ${ }^{1,2}$
}

\begin{abstract}
Background: The aim of the study was to evaluate patient reported outcome measures (PROM) before and after trapeziectomy with or without ligament reconstruction and tendon interposition for trapeziometacarpal joint arthritis with special focus on possible differences due to gender, age and surgical method.

Methods: Data from the Swedish quality registry for hand surgery (HAKIR) was analyzed preoperatively, 3 months and 1 year postoperatively for 1850 patients (mean age 63 years, 79\% women).

Results: One year postoperatively, mean pain at rest was reduced from 50 to 12 of maximum 100. However, pain on load and weakness had not abated to the same extent (mean 30 and 34 of 100, respectively). The mean improvement in PROM did not differ between age groups or gender. The result was similar after trapeziectomy with ligament reconstruction and tendon interposition (86\% of the patients) and simple trapeziectomy but few patients were operated with the latter method.

Conclusion: Pain on load and weakness remains to some extent 1 year after surgery for trapeziometacarpal joint arthritis. The result is similar after trapeziectomy with or without ligament reconstruction and tendon interposition and the same improvement can be expected after surgery regardless of age and gender.
\end{abstract}

Keywords: Trapeziometacarpal joint, CMC1, Thumb base, Osteoarthritis, Thumb, Patient reported outcome measures, Quality registry, Hand surgery

\section{Background}

The trapeziometacarpal joint (TMJ) is a common site of osteoarthritis, especially in elderly women $[1,2]$. When non-operative treatment is insufficient, trapeziectomy with ligament reconstruction and tendon interposition (LRTI) still remains the dominant surgical method, although the literature has not shown any advantages compared to simple trapeziectomy [3-7]. The effect of surgical interventions for TMJ osteoarthritis in terms of patient reported outcome measures (PROM) has been assessed with for example the Michigan Hand Outcomes Questionnaire (MHQ) [8], the Patient Evaluation Measure (PEM) [9], and most commonly the Disability of the

\footnotetext{
* Correspondence: maria.wilcke@sll.se

'Karolinska Institute, Department of Clinical Science and Education,

Södersjukhuset, Stockholm, Sweden

2Department of Hand surgery, Södersjukhuset, Sjukhusbacken 10, 11883

Stockholm, Sweden

Full list of author information is available at the end of the article
}

Arm, Shoulder and Hand (DASH) questionnaire [2, 10]. PROMs before and after surgery for TMJ osteoarthritis have previously not been studied in large patient materials.

The first national healthcare quality registry for hand surgery was started in Sweden in 2010 [11]. The registry is named HAKIR and includes all operations performed at the seven specialist departments of hand surgery in Sweden, as well as two private units. PROM questionnaires are issued to all operated patients before, as well as 3 and 12 months after surgery and include the QuickDASH [12] and an eight-item questionnaire (HQ-8) with seven questions rating perceived symptoms in the operated hand (pain on load, pain on motion without load, pain at rest, stiffness, weakness, numbness and cold sensitivity) and one question about the ability to perform activities of daily living (ADL) (Additional file 1). The responses are used as single items and are not calculated 
into a total score. The HQ-8 uses a nine-level Likert scale in 11 point increments ranging from 0 (no problem) to 100 (worst problem imaginable) and has been shown to have good psychometric properties in a yet unpublished study by Carlsson et al. (2019). The QuickDASH has shown similar precision as the full length DASH in upper extremity disorders [13].

The primary aim of this study was to evaluate what effect trapeziectomy with or without LRTI have on HQ-8 and QuickDASH scores in a large cohort of patients with TMJ osteoarthritis, with special focus on possible gender and age differences. The secondary aim was to investigate the practice of simple trapeziectomy vs. LRTI and potential differences in results in terms of HQ-8 and QuickDASH scores.

\section{Methods}

Registry data from HAKIR for all patients operated for TMJ arthritis (ICD10 code M18) from the start of the registry on February 1, 2010 to September 2, 2017 was analyzed. In total, 2980 operations were registered in 2610 patients. Only patients operated with trapeziectomy with or without LRTI were included. Hence, patients operated with other methods were excluded (Fig. 1). A concomitant major surgical procedure was also an exclusion criterion. However, patients undergoing minor concomitant surgeries such as trigger finger, carpal tunnel release, ganglion excision or fusion of the metacarpophalangeal joint of the thumb were not excluded from the analysis. In patients operated on bilaterally (on separate occasions), the second operation was excluded. Patients who had more than three recorded surgical interventions in the hand during the period were excluded to reduce the risk for other conditions affecting the PROM. The final study population included 1850 operations in 1850 patients operated unilaterally with trapeziectomy with or without LRTI. The type of LRTI could not be distinguished in the registered data.

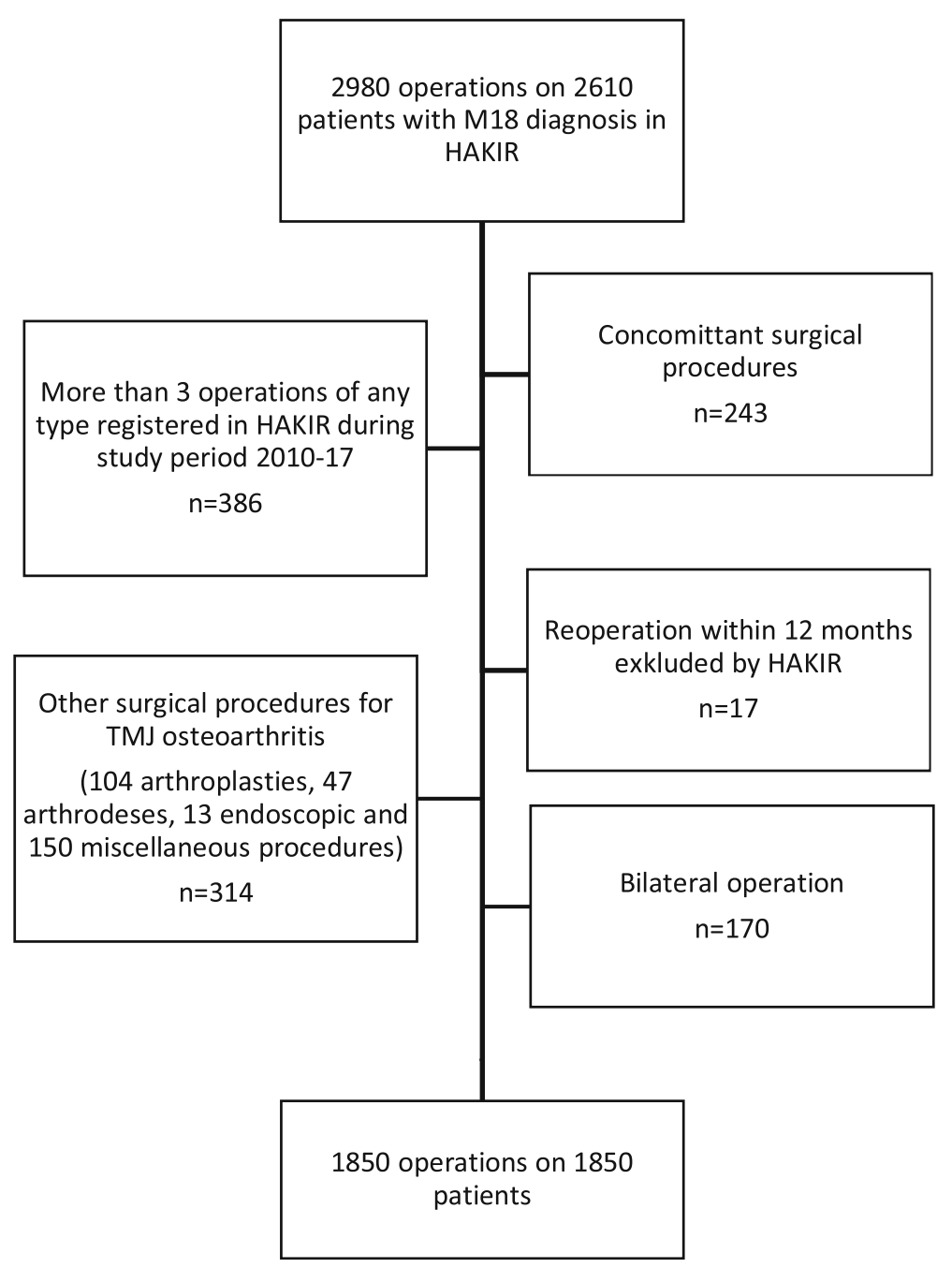

Fig. 1 Flow charts of the patients 
In HAKIR, patient questionnaires are issued either as a web-form or in a paper version that is posted to the patient. Patients who have been re-operated within 1 year, are below 16 years of age or persons that for cognitive reasons are unable to complete a questionnaire are excluded from the postoperative surveys. Response rates in HAKIR have varied from $43 \%$ in 2014 to $51 \%$ in 2017 (www.HAKIR.se). 46\% ( $n=852)$ of the 1850 patients had completed the questionnaire preoperatively, $42 \%(n=$ $774)$ at 3 months post-operatively and $37 \%(n=683) 1$ year after the operation.

The HQ-8 questionnaire items concerning pain on load, pain on motion without load, pain at rest, stiffness, weakness and ability to perform activities of daily living (ADL) as well as total score for the QuickDASH were evaluated.

PROM are presented as mean (SD) for all responses preoperatively, 3 months and 1 year postoperatively. The mean individual improvement in PROM from preoperatively to 1 year postoperatively is presented for patients with responses at both occasions. The patient material was dichotomized in two age groups at the mean age. Student's unpaired t-test (2-sided) was used for comparisons of PROM values between age groups, gender and surgical treatment. Missing data is not compensated for when all responses are presented and compared. Significance level was set at 0.05 .

An analysis of non-responders regarding age, gender and type of operation was made by comparing the patients that had answered the pain on load question preoperatively but not at 1 year to those that had answered this
Table 1 Baseline data

\begin{tabular}{llll}
\hline & All & Women & Men \\
\hline Number & 1850 & 1464 & 386 \\
Mean age (years) & 63 & 63 & 64 \\
Median age /years) & 63 & 62 & 64 \\
Range (years) & $28-93$ & $32-39$ & $28-89$ \\
Simple trapeziectomy & 250 & 189 & 61 \\
Trapeziectomy + LRTI & 1600 & 1275 & 325 \\
\hline
\end{tabular}

item at both occasions. Student's unpaired t-test (2-sided) and Chi-square test were used for these comparisons.

\section{Results}

Baseline data is presented in Table 1. The analysis on responders (337) vs. non-responders (515) showed the same distribution of gender and operation methods. The mean age of the non-responders was lower than the responders (62 vs. 64 years, $p<0.01$ ).

The PROM responses for all patients are shown in Fig. 2. Table 2 presents the mean PROM values, number of responses at the different times, and the mean individual change.

Patients 63 years or younger $(n=1015)$ reported significantly worse scores for pain (on load, on motion without load and at rest) and ADL preoperatively and significantly worse scores for all parameters except pain at rest and QuickDASH postoperatively compared to patients 64 years or older (Table 3). However, the differences were small and the mean individual reported improvement did not differ between the age groups.

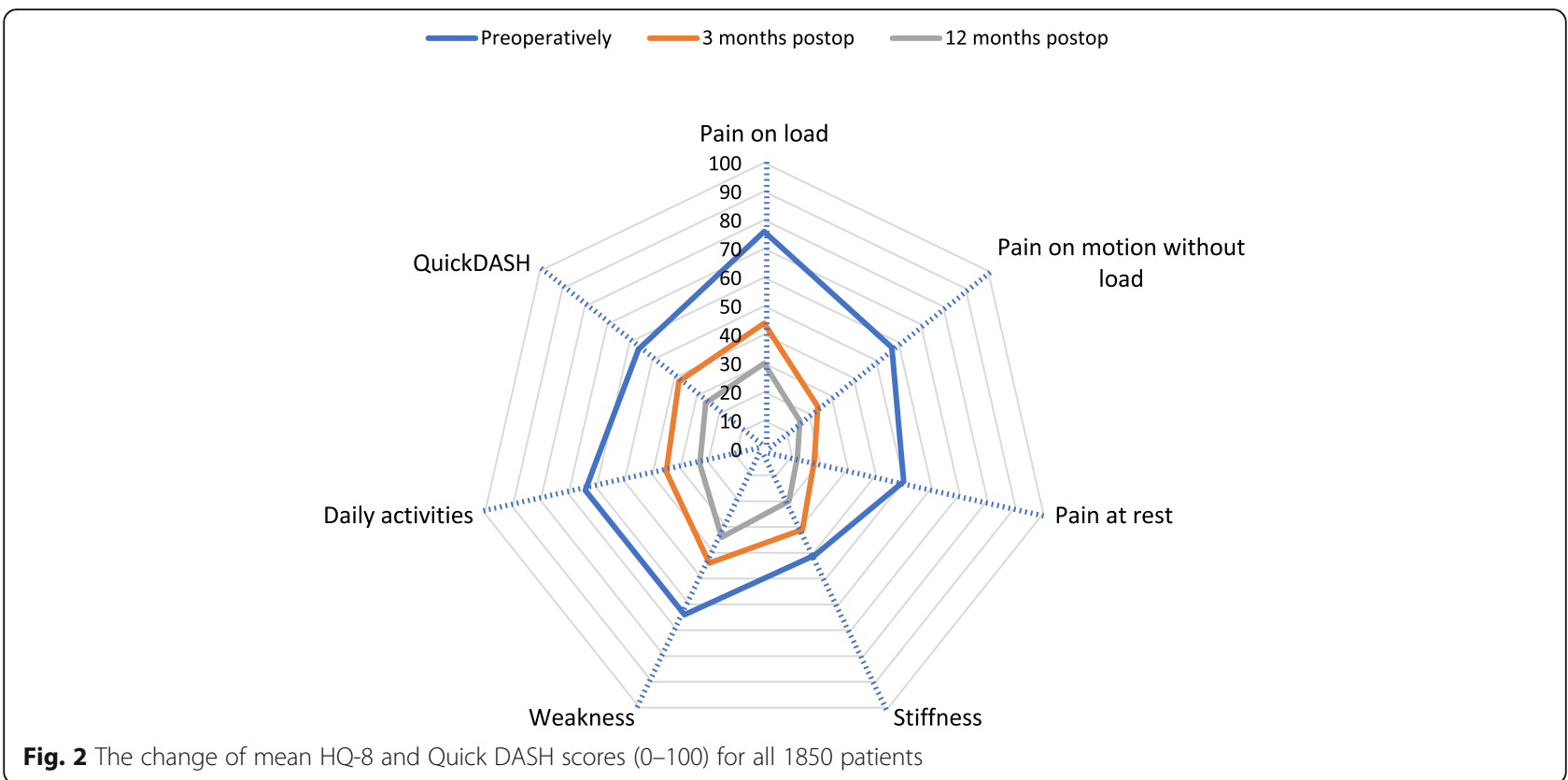


Table 2 The mean PROM values

\begin{tabular}{|c|c|c|c|c|c|c|c|c|}
\hline PROM & $\begin{array}{l}\text { Preop } \\
\text { PROM } \\
\text { mean (SD) }\end{array}$ & $\begin{array}{l}\text { No. of } \\
\text { responses } \\
\text { preop }\end{array}$ & 3 months PROM mean (SD) & $\begin{array}{l}\text { No. of } \\
\text { responses } \\
3 \text { months } \\
\end{array}$ & $\begin{array}{l}1 \text { year PROM } \\
\text { mean (SD) }\end{array}$ & $\begin{array}{l}\text { No. of } \\
\text { responses } \\
1 \text { year }\end{array}$ & $\begin{array}{l}\text { Mean individual } \\
\text { change (SD) preop } \\
-1 \text { year }\end{array}$ & $\begin{array}{l}\text { No. of responses } \\
\text { preop - } 1 \text { year }\end{array}$ \\
\hline Pain on load & $76(17)$ & 852 & $44(25)$ & 770 & $30(26)$ & 675 & $-44(29)$ & 337 \\
\hline $\begin{array}{l}\text { Pain on motion } \\
\text { without load }\end{array}$ & $57(22)$ & 851 & $24(22)$ & 774 & $16(22)$ & 679 & $-40(27)$ & 338 \\
\hline Pain at rest & $50(25)$ & 847 & $18(22)$ & 772 & $12(19)$ & 681 & $-36(28)$ & 336 \\
\hline Stiffness & $41(28)$ & 837 & $31(24)$ & 770 & $20(23)$ & 683 & $-18(33)$ & 337 \\
\hline Weakness & $64(24)$ & 847 & $44(26)$ & 770 & $34(27)$ & 678 & $-30(31)$ & 333 \\
\hline Daily activities & $64(23)$ & 850 & $35(26)$ & 770 & $24(25)$ & 677 & $-39(32)$ & 336 \\
\hline QuickDASH & $56(16)$ & 843 & $38(20)$ & 758 & $26(20)$ & 667 & $-31(19)$ & 330 \\
\hline
\end{tabular}

Prom values preoperatively, 3 months and 1 year postoperatively and the mean individual change. PROM values range from 0 (no problem) to 100 (worst problem imaginable)

The mean scores for the majority of symptoms were significantly higher preoperatively for women (Table 4). Postoperatively, women reported significantly higher scores concerning pain at rest, weakness, problems in $\mathrm{ADL}$ and QuickDASH. As for the age groups, the differences were small and the mean individual reported improvement was similar between genders.
At 3 months, stiffness, ADL and QuickDASH were significantly better in the simple trapeziectomy group but the differences were small and there were no differences in mean PROM scores between simple trapeziectomy and LRTI after 1 year (Table 5). The mean individual improvement according to operation type was not analyzed since there were only complete responses both

Table 3 PROM values according to age groups

\begin{tabular}{|c|c|c|c|c|c|}
\hline & $\begin{array}{l}\text { Age group } \\
\text { (years) }\end{array}$ & $\begin{array}{l}\text { Preoperative } \\
\text { mean (SD) }\end{array}$ & $\begin{array}{l}3 \text { months } \\
\text { mean (SD) }\end{array}$ & $\begin{array}{l}1 \text { year } \\
\text { mean }(S D)\end{array}$ & $\begin{array}{l}\text { Individual change Preop - } \\
1 \text { year mean (SD)* }\end{array}$ \\
\hline \multirow[t]{3}{*}{ Pain at load } & $28-63$ & $78(16)$ & $49(25)$ & $34(27)$ & $-44(29)$ \\
\hline & $64-93$ & $73(18)$ & $39(25)$ & $26(25)$ & $-44(30)$ \\
\hline & & $p<0.001$ & $p<0.001$ & $p<0.001$ & $p=0.83$ \\
\hline \multirow[t]{3}{*}{ Pain on motion without load } & $28-63$ & $60(21)$ & $26(23)$ & $18(22)$ & $-42(27)$ \\
\hline & $64-93$ & $54(23)$ & $21(21)$ & $13(21)$ & $-39(27)$ \\
\hline & & $p<0.001$ & $p<0.001$ & $p=0.005$ & $p=0.36$ \\
\hline \multirow[t]{3}{*}{ Pain at rest } & $28-63$ & $53(24)$ & $21(24)$ & $13(20)$ & $-39(27)$ \\
\hline & $64-93$ & $46(26)$ & $15(19)$ & $11(17)$ & $-33(28)$ \\
\hline & & $p<0.001$ & $p<0.001$ & $p=0.14$ & $p=0.06$ \\
\hline \multirow[t]{3}{*}{ Stiffness } & $28-63$ & $42(27)$ & $35(25)$ & $22(23)$ & $-18(35)$ \\
\hline & $64-93$ & $39(28)$ & $26(23)$ & $18(23)$ & $-19(32)$ \\
\hline & & $p=0.15$ & $p<0.001$ & $p=0.03$ & $p=0.72$ \\
\hline \multirow[t]{3}{*}{ Weakness } & $28-63$ & $65(22)$ & $48(25)$ & $37(26)$ & $-28(30)$ \\
\hline & $64-93$ & $63(25)$ & $39(25)$ & $32(27)$ & $-32(33)$ \\
\hline & & $p=0.37$ & $p<0.001$ & $p=0.01$ & $p=0.32$ \\
\hline \multirow[t]{3}{*}{$\mathrm{ADL}$} & $28-63$ & $67(23)$ & $39(26)$ & $26(26)$ & $-40(31)$ \\
\hline & $64-93$ & $61(24)$ & $31(24)$ & $21(24)$ & $-38(32)$ \\
\hline & & $p=0.001$ & $p<0.001$ & $p=0.02$ & $p=0.65$ \\
\hline \multirow[t]{3}{*}{ Quick DASH } & $28-63$ & $57(16)$ & $41(20)$ & $28(20)$ & $-31(18)$ \\
\hline & 64-93 & $56(16)$ & $34(20)$ & $25(20)$ & $-31(19)$ \\
\hline & & $p=0.09$ & $p<0.001$ & $p=0.06$ & $p=0.96$ \\
\hline
\end{tabular}

The mean PROM values preoperatively, 3 months and 1 year postoperatively and the mean individual change according to age groups. PROM values range from 0 (no problem) to 100 (worst problem imaginable) * The mean individual improvement in PROM from preoperatively to 1 year postoperatively is presented for patients with responses at both occasion 
Table 4 PROM values according to gender

\begin{tabular}{|c|c|c|c|c|c|}
\hline & Gender & Preoperative mean (SD) & $\begin{array}{l}3 \text { months } \\
\text { mean (SD) }\end{array}$ & $\begin{array}{l}1 \text { year } \\
\text { mean (SD) }\end{array}$ & Individual change Preop - 11 year mean (SD) \\
\hline \multirow[t]{3}{*}{ Pain at load } & women & $76(17)$ & $44(25)$ & $31(26)$ & $-43(39) n=280$ \\
\hline & men & $73(17)$ & $43(26)$ & $26(26)$ & $-49(25) n=57$ \\
\hline & & $p=0.06$ & $p=0.55$ & $p=0.08$ & $p=0.11$ \\
\hline \multirow[t]{3}{*}{ Pain on motion without load } & women & $59(22)$ & $24(22)$ & $16(21)$ & $-41(28) n=281$ \\
\hline & men & $52(24)$ & $21(22)$ & $15(22)$ & $-38(23) n=57$ \\
\hline & & $p<0.001$ & $p=0.10$ & $p=0.60$ & $p=0.51$ \\
\hline \multirow[t]{3}{*}{ Pain at rest } & women & $52(24)$ & $19(22)$ & $12(19)$ & $-37(29) n=279$ \\
\hline & men & $43(25)$ & $15(19)$ & $9(18)$ & $-33(23) n=57$ \\
\hline & & $p<0.001$ & $p=0.10$ & $p=0.05$ & $p=0.29$ \\
\hline \multirow[t]{3}{*}{ Stiffness } & women & $42(28)$ & $31(24)$ & $20(23)$ & $-18(33) n=281$ \\
\hline & men & $38(27)$ & $29(24)$ & $18(23)$ & $-19(32) n=56$ \\
\hline & & $p=0.21$ & $p=0.31$ & $p=0.42$ & $p=0.84$ \\
\hline \multirow[t]{3}{*}{ Weakness } & women & $66(23)$ & $44(26)$ & $36(27)$ & $-29(31) n=276$ \\
\hline & men & $58(27)$ & $42(25)$ & $28(25)$ & $-35(32) n=57$ \\
\hline & & $p<0.001$ & $p=0.46$ & $p=0.003$ & $p=0.19$ \\
\hline \multirow[t]{3}{*}{$\mathrm{ADL}$} & women & $65(23)$ & $36(25)$ & $24(25)$ & $-38(32) n=280$ \\
\hline & men & $59(23)$ & $31(27)$ & $19(24)$ & $-44(28) n=56$ \\
\hline & & $p=0.002$ & $p=0.04$ & $p=0.05$ & $p=0.18$ \\
\hline \multirow[t]{3}{*}{ QuickDASH } & women & $58(16)$ & $39(20)$ & $28(21)$ & $-31(20) n=273$ \\
\hline & men & $48(16)$ & $34(22)$ & $19(18)$ & $-31(18) n=57$ \\
\hline & & $p<0.001$ & $p=0.01$ & $p<0.001$ & $p=0,99$ \\
\hline
\end{tabular}

The mean PROM values preoperatively, 3 months and 1 year postoperatively and the mean individual change according to gender. PROM values range from 0 (no problem) to 100 (worst problem imaginable)

preoperatively and after 1 year in 39 patients with simple trapeziectomy ( $n=298$ patients with LRTI).

\section{Discussion}

One year after surgery for TMJ joint osteoarthritis, most patients had experienced a major reduction of pain at rest from a mean score of 50 to 12 and the mean QuickDASH score was reduced by more than half. However, patients should be informed that a complete resolution of pain on load and weakness not is to be expected 1 year after surgery (mean score 30 and 34, respectively). Younger patients and women reported slightly worse PROM both before and after surgery but the mean individual improvement in PROM did not differ between age groups or gender.

Our data may be used for preoperative patient information about the expected outcome after surgery. Further, the presented data can be useful as reference values for power calculations in the design of studies comparing interventions for TMJ joint osteoarthritis and also applied as benchmark values to which the results of observational studies can be compared.

The registry data confirmed that trapeziectomy and LRTI still is the prevailing surgical method in Sweden despite reports that LRTI has shown no advantage over simple trapeziectomy but rather a higher risk for complications $[2,4,14]$. Reports from the United States [6, 15] demonstrate the same tendency that clinical practice does not follow available evidence. The mean PROM values for all patients favored simple trapeziectomy at 3 months postoperatively regarding stiffness, ADL and QuickDASH but the differences were probably too small to be relevant. Results were similar 1 year postoperatively which is in line with former studies [2, 4, 14]. We could not make a well-founded comparison of the individual improvement after simple trapeziectomy versus LTRI due to low response rates and the fact that so few of the former method was performed. Thus, we cannot make any recommendations regarding surgical method based on this study. It was not possible to distinguish different type of LRTI in the data so LRTI:s were by necessity grouped as one category which might not be optimal. However, there is no solid evidence that results differ after various LRTI [3].

The strong point of this study is the large sample. This is valuable in analysis of subjective variables such as PROM that inherently have a large individual variance and might be affected by other factors such as depression 
Table 5 PROM values according to surgical method

\begin{tabular}{|c|c|c|c|c|c|c|c|}
\hline \multirow[t]{2}{*}{ PROM } & \multirow[t]{2}{*}{ Operation } & \multicolumn{2}{|c|}{ Preoperatively } & \multicolumn{2}{|c|}{3 months } & \multicolumn{2}{|c|}{1 year } \\
\hline & & $\mathrm{n}=$ & Mean (SD) & $n=$ & Mean (SD) & $\mathrm{n}=$ & Mean (SD) \\
\hline \multirow[t]{3}{*}{ Pain on load } & Trapeziectomy & 102 & $74(17)$ & 102 & $40(25)$ & 87 & $30(25)$ \\
\hline & LRTI & 750 & $76(17)$ & 668 & $45(25)$ & 588 & $30(26)$ \\
\hline & & & $p=0,38$ & & $p=0,07$ & & $p=0,99$ \\
\hline \multirow[t]{3}{*}{ Pain on motion without load } & Trapeziectomy & 102 & $53(25)$ & 103 & $21(21)$ & 87 & $16(22)$ \\
\hline & LRTI & 749 & $58(22)$ & 671 & $24(22)$ & 592 & $16(22)$ \\
\hline & & & $p=0,07$ & & $p=0,18$ & & $p=0,97$ \\
\hline \multirow[t]{3}{*}{ Pain at rest } & Trapeziectomy & 100 & $47(25)$ & 103 & $16(21)$ & 87 & $11(19)$ \\
\hline & LRTI & 747 & $50(25)$ & 669 & $18(22)$ & 594 & $12(19)$ \\
\hline & & & $p=0,29$ & & $p=0,37$ & & $p=0,78$ \\
\hline \multirow[t]{3}{*}{ Stiffness } & Trapeziectomy & 101 & $38(29)$ & 103 & $26(23)$ & 87 & $19(23)$ \\
\hline & LRTI & 736 & $41(27)$ & 667 & $37(24)$ & 596 & $21(23)$ \\
\hline & & & $p=0,32$ & & $p=0,02$ & & $p=0,65$ \\
\hline \multirow[t]{3}{*}{ Weakness } & Trapeziectomy & 103 & $64(25)$ & 102 & $41(24)$ & 86 & $35(25)$ \\
\hline & LRTI & 744 & $64(24)$ & 668 & $44(26)$ & 592 & $34(27)$ \\
\hline & & & $p=0,85$ & & $p=0,30$ & & $p=0,79$ \\
\hline \multirow[t]{3}{*}{ Daily activities } & Trapeziectomy & 102 & $62(22)$ & 101 & $30(23)$ & 86 & $23(25)$ \\
\hline & LRTI & 748 & $64(23)$ & 669 & $36(26)$ & 591 & $23(25)$ \\
\hline & & & $p=0,38$ & & $p=0,03$ & & $p=0,92$ \\
\hline \multirow[t]{3}{*}{ QuickDASH } & Trapeziectomy & 102 & $55(17)$ & 102 & $33(19)$ & 87 & $24(19)$ \\
\hline & LRTI & 741 & $56(16)$ & 656 & $39(20)$ & 580 & $26(20)$ \\
\hline & & & $p=0,49$ & & $p=0,01$ & & $p=0,37$ \\
\hline
\end{tabular}

The mean PROM values preoperatively, 3 months and 1 year postoperatively after simple trapeziectomy versus ligament reconstruction and tendon interposition (LRTI). PROM values range from 0 (no problem) to 100 (worst problem imaginable)

or other upper-extremity comorbidities [16, 17]. To reduce the uncertainty due to individual variance, we made paired analyses of the individual improvement in PROM. Due to low response rates and the fact that many patients did not respond at all three occasions, the samples were markedly reduced in the paired analyses and this affected in particular the comparison between surgical methods.

A problem with the large sample is that small differences in PROM that might not be clinically important, may reach statistical significance. The minimum clinically important difference (MCID) for QuickDASH was determined by Franchignoni et al. [18] to16 points. MCID for HQ-8 items have not yet been described. In general, MCID tend to be 0,5 SD [19]. We found (statistically) significantly worse PROM scores in younger patients and in women both before and after surgery, but none of the differences in the HQ-8 item scores were close to 0,5 SD. QuickDASH was significantly higher in women at all times but the difference was 10 points at most. The differences could be attributable to higher functional demands in younger patients and differing $\mathrm{ADL}$ and life-style habits, anatomical variability or pain perception between men and women but the differences may as well represent normal variation. Since the effect of the operation (i.e. improvement of PROM) did not differ between age groups or gender, we do not interpret our results as younger patients and female having an inferior result after operation.

Registry studies enable inclusion of many more patients than randomized controlled trials (RCTs), which often compare relatively few patients treated under strictly controlled conditions. Moreover, registry studies report the "real life" situation, including all types of patients, treated at different centers and operated by many different surgeons. For many hand conditions, RCTs is almost impossible to perform due to small populations and we believe that registry studies will be increasingly important in the field of hand surgery. On the other hand, potential confounders cannot not be controlled for in registry studies which might induce e.g. selection bias regarding surgical method.

A limitation of this study is that the sample did not include re-operated patients and we have no information on complication rates. Patients who sustained postoperative complications probably would have affected the patient reported outcomes negatively. Further, 1 year is a relatively short follow-up time and the result may change with time. Yeoman et al. [20] report a mean 
quick-DASH of 40 after 3,5-17 years after simple trapeziectomy which is considerably higher than in this sample (QuickDASH 26). The poor response rate is a major limitation of the HAKIR and thus of this study. The HQ-8 questionnaire is presently issued mainly by e-mail, as a web-survey. There is a risk that e-mails end up in spam filters or that patients are not motivated to respond. One reminder to answer the questionnaire is send by a sms. There is a risk that the older population answers web-surveys to a lesser extent. However, the mean age of the non-responders was actually lower than responders. For all ages, there is a risk for survey fatigue so simple questionnaires with few questions are probably favorable for a better response rate and we believe that the HQ- 8 fulfill this request. More information to patients about the registry and its purpose could be an incentive. Improved response rate is a crucial improvement needed for the HAKIR to reach its full potential to compare hand surgical interventions.

\section{Conclusion}

Good patient-reported outcomes, especially concerning pain at rest, can be expected 1 year after trapeziectomy with or without LRTI in most patients. Remaining symptoms may be pain on load and weakness. Further data needs to be collected for valid comparison between simple trapeziectomy and LRTI.

\section{Supplementary information}

Supplementary information accompanies this paper at https://doi.org/10. 1186/s12891-020-3045-7.

Additional file 1. HQ-8 questionnaire.

\section{Abbreviations}

ADL: Activities of daily living; DASH: Disability of the Arm, Shoulder and Hand; HAKIR: The Swedish quality registry for hand surgery; HQ-8: The HAKIR 8-item questionnaire; LRTI: Ligament reconstruction and tendon interposition; PROM: Patient reported outcome measures; TMJ: Trapeziometacarpal joint

\section{Acknowledgements}

Not applicable.

\section{Authors' contributions}

MR, MA and MÅ designed the study. All authors analyzed and interpreted the patient data. MW, MR and MA wrote the manuscript. All authors read and approved the final manuscript.

\section{Funding}

The authors have not received any funding for this study. Open access funding provided by Karolinska Institute.

\section{Availability of data and materials}

The datasets used and/or analyzed during the current study are available from the corresponding author on reasonable request.

\section{Ethics approval and consent to participate}

The study was approved by the Swedish Ethical Review Authority, local Ethics Committee of Stockholm (D.nr 2017/143-32).
Consent for publication

Not applicable.

\section{Competing interests}

The authors declare that they have no competing interests. No benefits of any kind have been received or will be received for personal or professional use from a commercial party related directly or indirectly to the article. Thus, no financial or other relationships exist that might lead to a conflict of interests.

\section{Author details}

'Karolinska Institute, Department of Clinical Science and Education, Södersjukhuset, Stockholm, Sweden. ${ }^{2}$ Department of Hand surgery, Södersjukhuset, Sjukhusbacken 10, 11883 Stockholm, Sweden. ${ }^{3}$ Region Skåne, Department of Data Analytics and Register Centrum, Lund, Sweden.

Received: 9 August 2019 Accepted: 6 January 2020

Published online: 01 February 2020

\section{References}

1. Sodha S, Ring D, Zurakowski D, Jupiter JB. Prevalence of osteoarthrosis of the trapeziometacarpal joint. J Bone Joint Surg Am. 2005;87:2614-8.

2. Wolf JM, Turkiewicz A, Atroshi I, Englund M. Prevalence of doctor-diagnosed thumb carpometacarpal joint osteoarthritis: an analysis of Swedish health care. Arthritis Care Res. 2014;66:961-5

3. Wajon A, Carr E, Edmunds I, Ada L. Surgery for thumb (trapeziometacarpal joint) osteoarthritis. Cochrane Database Systematic Reviews. 2015;23(2): CD004631.

4. Gangopadhyay S, McKenna H, Burke FD, Davis TR. Five- to 18-year follow-up for treatment of trapeziometacarpal osteoarthritis: a prospective comparison of excision, tendon interposition, and ligament reconstruction and tendon interposition. J Hand Surg Am. 2012;37:411-7.

5. Wolf JM, Delaronde S. Current trends in nonoperative and operative treatment of trapeziometacarpal osteoarthritis: a survey of US hand surgeons. J Hand Surg Am. 2012;37:77-82.

6. Yuan F, Aliu O, Chung KC, Mahmoudi E. Evidence-based practice in the surgical treatment of thumb carpometacarpal joint arthritis. J Hand Surg Am. 2017;42:104-12

7. Barthel L, Hidalgo Diaz JJ, Vernet P, Gouzou S, Facca S, Igeta Y, Liverneaux P. Results of the treatment of first carpometacarpal joint osteoarthritis: trapeziectomy alone versus trapeziectomy associated with suspensionplasty. Eur J Orthop Surg Traumatol. 2018;28:555-61.

8. Marks M, Hensler S, Wehrli M, Scheibler AG, Schindele S, Herren DB. Trapeziectomy with suspension-interposition Arthroplasty for thumb carpometacarpal osteoarthritis: a randomized controlled trial comparing the use of allograft versus flexor carpi Radialis tendon. J Hand Surg Am. 2017;42: 978-86.

9. Davis T, Pace A. Trapeziectomy for trapeziometacarpal joint osteoarthritis: is ligament reconstruction and temporary stabilisation of the pseudarthrosis with a Kirschner wire important? J Hand Surg Eur. 2009;34:312-21.

10. Hudak PL, Amadio PC, Bombardier C. Development of an upper extremity outcome measure: the DASH (disabilities of the arm, shoulder and hand) [corrected]. The upper extremity collaborative group (UECG). Am J Ind Med. 1996;29:02-8.

11. Arner M. Developing a national quality registry for hand surgery: challenges and opportunities. EFORT Open Reviews. 2016;1:100-6.

12. Beaton DE, Wright JG, Katz JN. Development of the QuickDASH: comparison of three item reduction approaches. J Bone Joint Surg Am. 2005;87:1038-46.

13. Gummesson C, Ward MM, Atroshi I. The shortened disabilities of the arm, shoulder and hand questionnaire (QuickDASH): validity and reliability based on responses within the full-length DASH. BMC Musculoskelet Disord. 2006; 7:44.

14. Vermeulen GM, Slijper H, Feitz R, Hovius SE, Moojen TM, Selles RW. Surgical management of primary thumb carpometacarpal osteoarthritis: a systematic review. J Hand Surg Am. 2011;36:157-69.

15. Aliu O, Davis MM, DeMonner S, Chung KC. The influence of evidence in the surgical treatment of thumb basilar joint arthritis. Plast Reconstr Surg. 2013; 131:816-28

16. London DA, Stepan JG, Boyer MI, Calfee RP. The impact of depression and pain catastrophization on initial presentation and treatment outcomes for atraumatic hand conditions. J Bone Joint Surg Am. 2014;96:806-14. 
17. Calfee R, Chu J, Sorensen A, Martens E, Elfar J. What is the impact of comorbidities on self-rated hand function in patients with symptomatic Trapeziometacarpal arthritis? Clin Orthop Relat Res. 2015;473:3477-83.

18. Franchignoni F, Vercelli S, Giordano A, Sartorio F, Bravini E, Ferriero G. Minimal clinically important difference of the disabilities of the arm, shoulder and hand outcome measure (DASH) and its shortened version (QuickDASH). J Orthop Sports Phys Ther. 2014;44:30-9.

19. Norman GR, Sloan JA, Wyrwich KW. Interpretation of changes in healthrelated quality of life: the remarkable universality of half a standard deviation. Med Care. 2003;41(5):582-92.

20. Yeoman TFM, Stone O, Jenkins PJ2, McEachan JE. The long-term outcome of simple trapeziectomy. J Hand Surg Eur 2018, 0: 1-5.

\section{Publisher's Note}

Springer Nature remains neutral with regard to jurisdictional claims in published maps and institutional affiliations.

Ready to submit your research? Choose BMC and benefit from:

- fast, convenient online submission

- thorough peer review by experienced researchers in your field

- rapid publication on acceptance

- support for research data, including large and complex data types

- gold Open Access which fosters wider collaboration and increased citations

- maximum visibility for your research: over $100 \mathrm{M}$ website views per year

At BMC, research is always in progress.

Learn more biomedcentral.com/submissions 